\title{
Helicobacter Pylori Eradication Therapy in both Erosive and Non-erosive Gastritis - A Prospective Study
}

\author{
Mohammad Quamrul Hasan ${ }^{1}$, M. M. Shahin-ul-Islam² ${ }^{2}$ Shahidul Hasan Mollick ${ }^{3}$, \\ Irin Perveen ${ }^{4}$, A. S. M. A. Raihan ${ }^{5}$ \\ Received: January 16, 2013 Accepted: September 14, 2013
}

\begin{abstract}
Background: Infection with Helicobacter pylori (H. pylori) is a recognized cause of peptic ulcer and gastritis. Persistence of infection is a definite risk factor for gastric malignancy. Healing of gastritis after eradication of $H$. pylori reduces the risks of peptic ulcer disease and gastric malignancy. Objectives: To find out the relationship of $H$. pylori with erosive and nonerosive gastritis, the effect of anti-H. pylori therapy and to compare the effects of anti-H. pylori therapy between two types of gastritis. Materials and Methods: This prospective study was done in the Gastroenterology department of Bangabandhu Sheikh Mujib Medical University, Dhaka from June 2008 to May 2009. One hundred eighty dyspeptic patients were enrolled for the study. Patients with gastritis diagnosed by endoscopy underwent rapid urease test (RUT). RUT positive patients were considered to have H. pylori infection and were treated with triple therapy (omeprazole, amoxycillin and metronidiazole) for 14 days. Treatment responses were assessed by clinical history and also by endoscopic biopsy and RUT. Results of endoscopic findings and RUT after treatment were compared with pretreatment status. Results: Seventy patients completed the treatment and finally could be assessed. Endoscopic findings of 70 patients revealed that 56 (80\%) patients had erosive gastritis and 14 (20\%) patients had nonerosive gastritis. After treatment, 47 (67.1\%) lesions became normal, 16 (22.9\%) remained erosive and $7(10 \%)$ non-erosive as before. Out of 14 non-erosive diseases, 7 became normal, while out of 56 erosive diseases 40 became normal. The erosive group responded significantly better than the non-erosive group $\left(\chi^{2}=32.766, p<0.001\right)$. Fifty nine $(84.3 \%)$ patients with gastritis showed negative urease test after treatment. Conclusion: Strong relation between $H$. pylori infection and gastritis was found. Majority were antral erosive gastritis. Erosive group responded better than non-erosive group.
\end{abstract}

Key words: Erosive gastritis, Non-erosive gastritis, H. pylori, Rapid urease test (RUT)

J Enam Med Col 2014; 4(1): 15-20

\section{Introduction}

Peptic ulcer disease and chronic gastritis are common disorders. Association between chronic gastritis and active duodenal ulcer is $100 \%$ compared to $50 \%$ in non-ulcer controls. ${ }^{1}$ About $75 \%$ of patients with chronic gastritis have been found to have $H$. pylori infection compared to $10 \%$ in those without

gastritis. The overall prevalence of $H$. pylori infection is $28.7 \%$ in superficial gastritis, $57 \%$ in erosive gastritis, $63 \%$ in gastric erosion, $80 \%$ in gastric ulcer and $52.4 \%$ in early gastric cancer. ${ }^{2}$ The number of antral $H$. pylori organisms is associated with severity of chronic gastritis. 3,4

1. Associate Professor, Department of Gastroenterology, Enam Medical College \& Hospital, Savar, Dhaka

2. Assistant Professor, Department of Gastroenterology, Faridpur Medical College \& Hospital, Faridpur

3. Registrar, Department of Medicine, Shahid Ziaur Rahman Medical College \& Hospital, Bogra

4. Associate Professor, Department of Gastroenterology, Enam Medical College \& Hospital, Savar, Dhaka

5. Professor, Department of Gastroenterolgy, Bangabandhu Skeikh Mujib Medical University, Dhaka

Correspondence Mohammad Quamrul Hasan, Email: qhasanbd@gamil.com 
There are certain subtle changes in gastric mucosa which can be due to $H$. pylori and these changes are evaluated to predict the presence of $H$. pylori. According to modified Sydney system of classification, the "abnormal" looking endoscopic features of gastric mucosa are erythema/exudation, erosion (raised or flat), mosaic pattern or cobble stoning, hypertrophic rugae, atrophic (thinning of the mucosa accompanied by visibility of ramifying vessels) and nodular appearance. ${ }^{5}$

White-base lesions, raised or flat, surrounded by a margin of intense erythema are designated as erosive gastritis. Unequivocal eythema/exudation, mosaic pattern, hypertrophic rugae, atrophic and nodular appearance at endoscopy are features of non-erosive gastritis. ${ }^{5}$ The rapid urease test (RUT) can detect $H$. pylori within one hour with a satisfactory accuracy $(>90 \%)$ and is acceptable to initiate eradication therapy. 6

Combined antibiotic therapy is routinely used to treat H. pylori infection. The success of treatment in $H$. pylori infection depends mainly on antibiotic sensitivity. Triple therapy, including two antibiotics, amoxycillin and clarithromycin, and a proton pump inhibitor (PPI) given for 2 weeks has been recommended as the treatment of choice at several concensus conferences, but increasing antibiotic resistance is a problem. 6,7

The aim of the study was to find out the relationship of $H$. pylori infecion with erosive and non-erosive gastritis, effect of anti-H. pylori therapy on both types of gastritis and also to compare the effects of anti-H. pylori therapy on erosive and non-erosive gastritis.

\section{Materials and Methods}

This prospective study was conducted in the Gastroenterology department of Bangabandhu Sheikh Mujib Medical University (BSMMU), Dhaka during the period of June 2008 to May 2009. Patients aged 15-60 years having symptoms of dyspepsia, willing to undergo upper gastrointestinal (GI) endoscopy and anti- $H$. pylori therapy were enrolled in this study. Patients who were regular users of NSAID and steroids, had peptic ulcer and its complications, had history of previous $H$. pylori eradication therapy, and also patients with coexisting gastric carcinoma, pregnancy or lactation and concomitant other severe diseases were excluded from the study. Every ethical issues were discussed and informed written consents were taken from all patients.

\section{History and physical examination}

After taking history and physical examination, patients were referred for upper GI endoscopy. Patients receiving PPI, $\mathrm{H}_{2}$-receptor blocker $\left(\mathrm{H}_{2} \mathrm{RB}\right)$ and antibiotic were advised to come for endoscopy after stopping these drugs for at least two weeks.

\section{Upper GI endoscopy}

Selected patients underwent upper GI video endoscopy by experienced gastroenterologists. Endoscopic inflammation was defined as the presence of visible alterations of the mucosal appearance, presumably caused by vascular or infiltrative changes. Endoscopic or macroscopic inflammation was diagnosed when at least one of the abnormalities described below was unequivocally visible, either focally or diffusely, but most often a combination of abnormalities was found. White-base lesion (raised or flat) surrounded by a margin of intense erythema was designated as erosive gastritis. The intervening mucosa was usually normal or simply erythematous. Unequivocal eythema/exudation, mosaic pattern, hypertrophic rugae, atrophic and nodular appearance at endoscopy were designated as features of non-erosive gastritis. Endoscopic findings suggestive of erosive and non-erosive gastritis were documented with the clinical history. Biopsy specimens were collected from the predominant site of gastritis and rapid urease tests (RUT) for H. pylori were done instantly. Following findings were noted on the data sheet.

-Erosive gastritis

-Non-erosive gastritis

- Topography of gastritis (antral predominant, corpus/body predominant and diffusely distributed) 


\section{Rapid urease test (RUT)}

RUT was done with one of the specimens of the predominant site of gastritis using CLO test (Campylobacter-like organism test) kit for diagnosis of gastritis and was repeated four weeks after the completion of anti-H. pylori therapy. H. pylori status was defined by RUT.

\section{H. pylori eradication therapy}

All the patients with erosive and non-erosive gastritis with positive RUT were treated with anti-H. pylori therapy consisting of omeprazole (20 $\mathrm{mg}$ bd), metronidazole (500 $\mathrm{mg}$ bd) and amoxycillin (1 gm bd) for 14 days.

\section{Follow-up}

Follow-up visits were made for compliance and sideeffects. After completion of therapy, clinical history was again taken and compared against the pretreatment symptoms. Follow-up endoscopy was performed at least four weeks after completion of therapy. At least two weeks period, free of any PPI, $\mathrm{H}_{2} \mathrm{RB}$ or antibiotics prior to follow-up endoscopy were ensured. Improvement in the endoscopy findings was noted and compared with pre-treatment findings. Biopsy specimens were collected from antrum of the stomach for RUT.

\section{Statistical analysis}

Frequency of $H$. pylori infection was calculated among endoscopically proven gastritis patients. Clinical features, endoscopic findings, pre- and posttreatment disease status were compared. SPSS (Statistical Package for Social Services) 10.0 was used for statistical calculations.

\section{Results}

Total 180 dyspeptic patients underwent upper GI endoscopy. One hundred and ten patients had gastritis of which 79 had erosive and 31 had nonerosive gastritis (Table I). Among 110 gastritis patients, $78(71 \%)$ were RUT positive and $32(29 \%)$ were RUT negative (Table I). Out of $78 \mathrm{H}$. pylori positive patients $59(76 \%)$ with erosive and $19(24 \%)$ with non-erosive gastritis were treated and followedup subsequently. During the course of treatment eight patients were dropped-out. Finally, 70 patients returned for follow-up after completion of therapy and biopsy was taken from antrum for RUT.

Table I: Endoscopic findings of dyspeptic patients $(\mathrm{N}=180)$ and results of rapid urease test $(\mathrm{N}=110)$

\begin{tabular}{|l|c|c|}
\hline & Frequency & Percentage \\
\hline $\begin{array}{l}\text { Endoscopic findings } \\
\text { (N=180) }\end{array}$ & & \\
\hline Normal & 70 & 38.9 \\
\hline Erosive & 79 & 43.9 \\
\hline Non-erosive & 31 & 17.2 \\
\hline Results of rapid urease & & \\
\hline test (N=110) & & \\
\hline Positive & 78 & 71 \\
\hline Negative & 32 & 29 \\
\hline
\end{tabular}

Before treatment, $78.6 \%$ patients complained of abdominal pain and discomfort, $72.9 \%$ had bloating, $58.6 \%$ had early satiety, $57.1 \%$ had nausea, $54.3 \%$ had anorexia and $14.3 \%$ had vomiting (Table II). After treatment symptoms of pain and discomfort, bloating, early satiety, nausea, anorexia and vomiting resolved in $18.6 \%, 10 \%, 7.2 \%, 17.1 \%, 2.9 \%$ and $2.9 \%$ patients respectively and improved in $45.7 \%$, $42.9 \%, 35.7 \%, 27.2 \%, 30 \%$ and $8.5 \%$ patients respectively (Table II).

Before treatment, endoscopy of 70 patients revealed that $56(80 \%)$ had erosive gastritis and $14(20 \%)$ had non-erosive gastritis. Regarding sites of lesions, $81.5 \%$ were in the antrum, $11.4 \%$ in the body and $7.1 \%$ were diffusely distributed (Table III). After treatment, $59(84.3 \%)$ patients exhibited negative RUT (Table IV) and 47 (67.1\%) lesions became normal, $16(22.9 \%)$ remained erosive and $7(10 \%)$ non-erosive. Out of 56 erosive cases 40 became normal and out of 14 non-erosive cases seven became normal. The erosive group responded significantly better than the non-erosive group $\left(\chi^{2}=32.766, p<0.001\right)($ Table V). 
Table II: Distribution of patients by clinical presentation $\left(\mathrm{n}=70^{*}\right)$

\begin{tabular}{|c|c|c|c|c|c|}
\hline \multirow[t]{2}{*}{ Clinical presentation } & \multirow[t]{2}{*}{$\begin{array}{l}\text { Before treatment } \\
\text { Frequency }(\%)\end{array}$} & \multicolumn{4}{|c|}{$\begin{array}{l}\text { After treatment } \\
\text { Frequency }(\%)\end{array}$} \\
\hline & & Resolved & Improved & No change & Deteriorated \\
\hline $\begin{array}{l}\text { Abdominal pain and } \\
\text { discomfort }\end{array}$ & $55(78.6)$ & $13(18.6)$ & $32(45.7)$ & $9(12.9)$ & $1(1.4)$ \\
\hline Bloating & $51(72.9)$ & $7(10)$ & $30(42.9)$ & $14(20)$ & - \\
\hline Early satiety & $41(58.6)$ & $5(7.2)$ & $25(35.7)$ & $11(15.7)$ & - \\
\hline Nausea & $40(57.1)$ & $12(17.1)$ & $19(27.2)$ & $8(11.4)$ & $1(1.4)$ \\
\hline Anorexia & $38(54.3)$ & $2(2.9)$ & $21(30)$ & $14(20)$ & $1(1.4)$ \\
\hline Vomiting & $10(14.3)$ & $2(2.9)$ & $6(8.5)$ & $2(2.9)$ & - \\
\hline
\end{tabular}

*Total figure will not correspond to frequency and percentage shown as many patients had multiple presentations

Table III: Pre-treatment endoscopic findings $(n=70)$

\begin{tabular}{|l|c|c|}
\hline Endoscopic findings & Frequency & Percentage \\
\hline Types & & \\
\hline Erosive & 56 & 80.0 \\
Non-erosive & 14 & 20.0 \\
\hline Sites of lesions & & \\
Antrum & 57 & 81.5 \\
Corpus & 08 & 11.4 \\
Diffuse & 05 & 7.1 \\
\hline
\end{tabular}

Table IV: Rapid urease test after treatment $(\mathrm{n}=70)$

\begin{tabular}{|l|c|c|}
\hline Rapid urease test & Frequency & Percentage \\
\hline Positive & 11 & 15.7 \\
\hline Negative & 59 & 84.3 \\
\hline
\end{tabular}

Table V: Comparison of disease status (gastritis) before and after treatment $(\mathrm{n}=70)$

\begin{tabular}{|c|c|c|c|c|}
\hline \multicolumn{4}{|c|}{$\begin{array}{l}\text { After } \\
\text { treatment }\end{array}$} & $\begin{array}{l}\text { Before } \\
\text { treatment }\end{array}$ \\
\hline & Erosive & Nonerosive & Normal & \\
\hline Erosive & 16 & 00 & 40 & $\begin{array}{c}56 \\
(80.0)\end{array}$ \\
\hline Nonerosive & 00 & 07 & 07 & $\begin{array}{c}14 \\
(20.0)\end{array}$ \\
\hline Total & $\begin{array}{c}16 \\
(22.9)\end{array}$ & $\begin{array}{c}07 \\
(10.0)\end{array}$ & $\begin{array}{c}47 \\
(67.1)\end{array}$ & $\begin{array}{c}70 \\
(100.0)\end{array}$ \\
\hline
\end{tabular}

Figures in the parentheses indicate percentages McNemar $\chi^{2}=32.766, p<0.001$

\section{Discussion}

H. pylori is a recognized cause of peptic ulcer and gastritis and definite risk factor for carcinoma stomach and MALT (mucosa associated lymphoid tissue) lymphoma. ${ }^{8}$ Eradication of $H$. pylori in infected persons causes significant improvement of gastritis and gastric atrophy. It also reduces the risks of malignancy and even causes complete remission of low grade MALT lymphoma. ${ }^{9}, 10$ So $H$. pylori infection and $H$. pylori gastritis should be identified and treated.

In most persons, H. pylori infection is largely restricted to the gastric antrum. Studies showed that H. pylori occurs in the antrum in at least $85 \%$ of patients with the disease, and in up to $15 \%$ of patients the organism is found only in the corpus. ${ }^{11,12}$ We found that $81.5 \%$ of RUT positive gastritis were located at antrum, $11.4 \%$ on the body of stomach, and $7.1 \%$ were diffusely distributed.

There is a great deal of ignorance about the normal macroscopic appearance of the gastric mucosal lining. Many of the appearances which endoscopists interprete as "Normal" are presumably not normal. ${ }^{12,13}$ Endoscopic findings such as erythema are frequently labeled as gastritis despite a long recognized lack of evidence supporting a correlation between endoscopic features and histologic gastritis. ${ }^{14}$ Some authors believe that there are certain subtle changes in gastric mucosa which can be due to H. pylori. ${ }^{15}$

In this study, we found that $80 \%$ had erosive gastritis and $20 \%$ non-erosive gastirits; all were RUT positive H. pylori gastritis. White-base lesion (raised or flat) 
surrounded by a margin of intense erythema was designated as erosive gastritis. Unequivocal eythema/exudation, mosaic pattern, hypertrophic rugae, atrophic and nodular appearance at endoscopy were designated as features of non-erosive gastritis. Perhaps up to $40 \%$ or more of patients with endoscopically normal mucosa have histological gastritis visible on biopsy. ${ }^{5}$ When erythema is the most conspicuous endoscopic abnormality, histologic chronic gastritis has been found in $75 \%$ or more of patients. ${ }^{13}$

When the endoscopic changes are more pronounced and erosions or frank atrophic gastritis are present, there are almost always corresponding histologic inflammatory changes. In general, the more severe the endoscopic gastric abnormality, the better the correlation with histology. ${ }^{14,16}$ In this study we followed Sydney system - endoscopic appearance of gastritis for diagnosis of gastritis without histology. ${ }^{5}$

Khan et $\mathrm{al}^{16}$ observed that the erythematous gastritis was the commonest single endoscopic finding and $H$. pylori was present in $74 \%$ of cases. Stolte and Edit ${ }^{17}$ concluded that chronic erosion of the antral mucosa represents sequelae of $H$. pylori gastritis, and these H. pylori induced chronic erosion which in future would be differentiated from other erosions. The antral erosion showed the specificity of $92 \%$ and sensitivity of $22 \%$ with positive predictive value of $86 \%$ to $H$. pylori infection. The raised erosions were more precisely associated with $H$. pylori infection than flat erosions. H. pylori was strongly associated with gastritis $2,75 \%$ patients with gastritis were positive compared with $10 \%$ without gastritis $(\mathrm{p}<0.001)$. In this study, H. pylori infection rate in gastritis was $71 \%$.

In eradication studies ${ }^{18}$ there is continuing debate whether dyspeptic symptoms diminish with anti- $H$. pylori treatment. This is partly because of the high placebo-response rate and partly because many treatment regimens have not cured the infection. Suppression of bacterial growth may not affect symptoms significantly, if these are due to mucosal inflammation, and symptom resolution may take many weeks or months following cure of $H$. pylori and the associated gastritis.

In the present study, symptoms of pain and discomfort, bloating, early satiety, nausea, anorexia and vomiting resolved in $18.6 \%, 10 \%, 7.2 \%, 17.1 \%, 2.9 \%$ and $2.9 \%$ patients respectively and improved in $45.7 \%, 42.9 \%$, $35.7 \%, 27.2 \%, 30 \%$ and $8.5 \%$ patients respectively after treatment. Dyspeptic symptoms improvement due to treatment of $H$. pylori was doubtful, but may be related to placebo effects of drugs.

According to the Maastricht III consensus conference 2005, it was recommended that diagnosis is confirmed and treatment can be started if RUT is positive. ${ }^{6}$ There are a number of commercially available RUT kits with overall pretreatment sensitivities of $>90 \%$ and specificities of $>95 \%{ }^{19}$ and these are sufficient to justify its use as a single test for H. pylori.

The simplicity, low cost, and relatively rapid results make the RUT a practical and cost-effective means of testing for $H$. pylori in patients not taking antibiotics, bismuth, or PPIs who require upper GIT endoscopy. For these reasons, RUT was used as single test for diagnosis of $H$. pylori gastritis in this study.

Due to patchy distribution of $H$. pylori infection after antibiotics or PPIs, biopsy for the RUT should be taken from two sites, the body at the gastric angularis and greater curvature of the antrum. ${ }^{20}$ Due to lack of facilities, we took biopsy from only predominant site of gastritis before treatment and only from antrum after treatment for RUT for diagnosis and assessment of eradication respectively.

In the current study, H. pylori status was considered to be positive by positive RUT. According to this criterion, out of 110 endoscopically proven gastritis patients, $71 \%$ had $H$. pylori gastritis. The remaining $29 \%$ patients were negative for RUT. This discordant result might be due to noncompliance of patients regarding prior use of PPI, $\mathrm{H}_{2} \mathrm{RB}$, antibiotics or gastritis due to some other causes.

Non-invasive tests like urea breath test and stool antigen test should be employed for confirmation of eradication except in cases where repeat endoscopy is indicated, for example in patients with gastric ulcer. ${ }^{19}$ As repeat endoscopy was done to see the changes of gastritis after triple therapy, RUT tests were done for confirmation of eradication.

The treatment of $H$. pylori is a challenging clinical problem due to antimicrobial resistance and falling eradication rates. The third Maastricht Consensus Report agreed that effective treatment for $H$. pylori should achieve an intention-to-treat (ITT) eradication 
rate of over $80 \% .{ }^{6}$ However, in clinical practice eradication rates are lower than $80 \%$ for many of the standard treatment regimes. A number of factors such as duration of treatment, choice of antibiotics, new drug combination, improved patient compliance and novel agents may help to improve eradication rates. 6,7

We used PPI-amoxycillin-metronidazole for 14 days as anti-H. pylori regimen in this study. This regimen was chosen as majority of our patients were poor. In this regimen the eradication rate was $89 \%$ and $64 \%$ for metronidazole susceptible and resistant strains, respectively. In a clinical trial using anti-H. pylori treatment, the global eradication rate was $64 \%{ }^{21}$ This study showed that $84.3 \%$ of $H$. pylori gastritis exhibited negative RUT tests 4 weeks after treatment with triple therapy. We assumed that eradication rate after treatment was $84 \%$. In the present study, strong relationship between $H$. pylori infection and gastritis was found. Majority cases had antral erosive gastritis. After treatment with $H$. pylori eradication therapy, significant improvement of endoscopic feature of gastritis occurred and erosive group responded better than non-erosive group.

\section{References}

1. Hui WM, Lam SK, Ho J, Matthew MN, Lui I, Lai CI et al. Chronic antral gastritis in duodenal ulcer. Natural history and treatment with prostaglandin E. Gastroenterology 1986; 91: 1095-1101.

2. Zhang C, Yamada N, Wu Y, Wen M, Matsuhisa T, Matsukura N. Helicobactor pylori infection, glandular atrophy and intestinal metaplasia in superficial gastritis, gastric erosion, gastric ulcer, and early gastric cancer. World J Gastroenterol 2005; 11: 791-796.

3. Buck GE, Gourley WK, Lee WK. Relation of Campylobacter pyloridis to gastritis and peptic ulcer. J. Infect. Dis.1986; 152: 664-669.

4. Bayerdroffer E, Oertrel H, Lehn N. Tropographic association between active gastritis and Campylobacter pylori colonization. J. Clin. Pathol. 1989; 42: 834-839.

5. Tytgat GNJ. The Sydney system: endoscopic division. Endoscopic appearances in gastritis/duodentitis. J Gastroenterol Hepatol 1991; 6: 223-224.

6. Malfertheiner P, Megraud F, O’Morain C, Bazzoli F, ElOmar E. The European Helicobacter Study Group (EHSG). Current concepts in the management of Helicobacter pylori infection: the Maastricht III Consensus Report. Gut 2007; 56: 772-781.
7. Chey WD, Wong CY. The Practice Parameters Committee of the American College of Gastroenterology. American College of Gastroenterology guideline on the management of Helicobacter pylori infection. Am J Gastroenterol 2007; 102: 1808-1825.

8. Helicobacter and Cancer Collaborative Group. Gastric cancer and Helicobacter pylori: a combined analysis of 12 case control studies nested within prospective cohorts. Gut 2001; 49: 347-353.

9. Rokkas T, Pistiolas D, Sechopoulos P, Robotis I, Margantinis G. The long-term impact of Helicobacter pylori eradication on gastric histology: a systematic review and meta-analysis. Helicobacter 2007; 12(Suppl. 2): 32-38.

10. Moss SF, Malfertheiner P. Helicobacter and gastric malignancies. Helicobacter 2007; 12(Suppl. 1): 23-30.

11. Moss SF, Sood S. Helicobacter pylori. Curr Opin Infect Dis 2003; 16: 445-451.

12. Fung WP, Papadimitrionu JM, Matz LR. Endoscopic, histological and ultrastructural correlations in chronic gastritis. Amer. J. Gastroent. 1979; 71: 269-279.

13. Taor RE, Fox B, Ware J, Johnson AG. Gastritis: gastroscopic and microscopic. Endosc 1975; 7: 209-215.

14. Sauerbructh T, Schreiber MA, Schussler P, Permanetter W. Endoscopy in the diagnosis of gastritis. Diagnostic value of endoscopic criteria in relation to histological diagnosis. Endosc 1984; 16: 101-104.

15. Khan MQ, Alhomsi Z, Al-Momen S, Ahmad M. Endoscopic features of Helicobacter pylori induced gastritis. Indian J Gastroenterology 1999; 5: 9-14.

16. Myren J, Hanssen AS. The gastroscopic diagnosis of gastritis with particular reference to mucosal reddening and mucous covering. Scand. J. Gastroenterol. 1974; 9: $457-462$.

17. Stolte M, Eidt S. Chronic erosions of the antral mucosa: a sequelae of $H$. pylori-induced gastritis. Z-Gastroenterol 1992; 30: 846-850.

18. Armstrong DS. Helicobacter pylori infection and dyspepsia. Scand J Gastroenterol Suppl. 1996; 215: $38-47$.

19. Perna F, Ricci C, Gatta L. Diagnostic accuracy of a new rapid urease test (Pronto Dry), before and after treatment of Helicobacter pylori infection. Minerva Gastroenterol Dietol 2005; 51: 247-254.

20. Woo JS, el-Zimaity HM, Genta RM. The best gastric site for obtaining a positive rapid urease test. Helicobacter 1996; 1: 256-259.

21. Lamouliatte H, Megraud F, Delchier JC. Second-line treatment for failure to eradicate Helicobacter pylori: a randomized trial comparing four treatment strategies. Aliment Pharmacol Ther 2003; 18: 791-797. 